Article

\title{
Cloning, Expression and Characterization of a Novel Fructosyltransferase from Aspergillus oryzae ZZ-01 for the Synthesis of Sucrose 6-Acetate
}

\author{
Tao Wei, Shen Huang, Jie Zang, Chunxiao Jia and Duobin Mao * \\ School of Food and Biological Engineering, Zhengzhou University of Light Industry, 5 Dongfeng Rd, \\ Zhengzhou 450002, China; weit8008@zzuli.edu.cn (T.W.); 2014110@zzuli.edu.cn (S.H.); pds0188@126.com (J.Z.); \\ yinghua228@126.com (C.J.) \\ * Correspondence: duobinmao@126.com; Tel./Fax: +86-371-8660-9631
}

Academic Editor: David D. Boehr

Received: 26 March 2016; Accepted: 4 May 2016; Published: 9 May 2016

\begin{abstract}
A 1521 bp gene encoding for a novel fructosyltransferase from Aspergillus oryzae ZZ-01 (AoFT) has been amplified by RACE and TAIL PCR, and functionally overexpressed in Escherichia coli BL 21-CodonPlus (DE3)-RIL. The recombinant $A$. oryzae ZZ-01 fructosyltransferases (r- $A$ oFT) was purified to homogeneity after Ni-NTA affinity and Superdex-200 gel filtration chromatography. SDS-PAGE analysis of the purified $\mathrm{r}-A o$ FT revealed a single protein band with an apparent molecular mass of $60.0 \mathrm{kDa}$. The r-AoFT enzyme exhibited its optimal activity at $55^{\circ} \mathrm{C}$ and $\mathrm{pH} 5.5$, and maintained about $63 \%$ of its activity even after $60 \mathrm{~min}$ of treatment at $60{ }^{\circ} \mathrm{C}$. The addition of $\mathrm{Mg}^{2+}$ led to an increase in the activity of $\mathrm{r}-A o \mathrm{FT}$, whereas $\mathrm{Zn}^{2+}, \mathrm{Cu}^{2+}$ and $\mathrm{Ni}^{2+}$ led to a reduction in its activity. Six site-directed mutants of r-AoFT (D39A, D164A, E216A, N38L, S99A and Y282A) were constructed and characterized biochemically. The N38L, S99A and Y282A mutants had lower $\mathrm{K}_{\mathrm{m}}$ and higher $V_{\text {max }}$ values than the wild-type enzyme, highlighting their higher binding affinity for the substrates. These results therefore suggest that $\mathrm{r}-A o$ FT could be used for the enzymatic synthesis of Suc6A from sucrose and glucose 6-acetate.
\end{abstract}

Keywords: fructosyltransferase; Aspergillus oryzae; gene cloning; site-directed mutagenesis; characterization

\section{Introduction}

Sucrose esters, which consist of a hydrophilic sucrose group and one to eight lipophilic fatty acid groups, are used in a wide variety of applications in the food, agricultural, cosmetic, detergent and pharmaceutical industries [1,2]. Sucrose 6-acetate (Suc6A) is a short-chain monoester and an important intermediate in the synthesis of sucralose, which is one of the sweetest sweeteners reported to date [3]. There are currently two main methods available for the synthesis of Suc6A, including chemical and enzymatic protocols. The traditional chemical procedure for the synthesis of Suc6A involves a complicated process that requires harsh separation techniques, which leads to several key limitations, including high energy consumption, browning of the products and the production of toxic byproducts [4,5]. Recent developments in the use of biological methods to affect specific chemical reactions have resulted in the development of enzymes for the synthesis of Suc6A. The enzymatic synthesis of Suc6A has several critical advantages over chemical synthesis in terms of providing higher specificity and efficiency, which could help to alleviate some of the aforementioned problems [6,7].

Fructosyltransferases (FTases, E.C. 2.4.1.9) can be used to catalyze the cleavage of the $\beta-(1,2)$-glycosidic linkages between glucose and fructose units, as well as the transfer of the resulting fructosyl group from one sucrose unit to another [8-10]. FTase coding genes have been isolated from several species, including plants [11-13], fungi [1,8,14,15] and bacteria [16-18], where they encode for 
extra- or intracellular FTases representing the eight highly conserved motifs in the glycoside hydrolases belonging to glycoside hydrolase families 32 (GH32) and 68 (GH68) [1,19]. The majority of the ftase genes reported to date have been isolated from Aspergillus strains of fungi, although a recent database mining analysis identified ftase-related sequences in the genomes of Gibberella zeae, Magna porthe grisea and Ustilago maydis [19]. The Aspergillus genes become increasingly homogeneous at sizes in the range of 1.6-2.2 kb and encode for enzymes of about 600 amino acids in length [8,19-21]. In bacteria, the ftase genes vary in size from $1.2 \mathrm{~kb}$ in Thermotoga maritima [22] up to $4.4 \mathrm{~kb}$ in Leuconostoc citreum [23], producing enzymes containing 432 and 1466 amino acids, respectively. In plants, the fructooligosaccharide (FOS)-related genes and enzymes contain approximately $2.0 \mathrm{~kb}$ and 680 amino acids, respectively [11,24,25]. Although several studies have been conducted to date pertaining to the computational analysis of these sequences, these studies have focused on a limited number of organisms [26,27]. The identification of new FTase-producing microorganisms with higher transfructosylation activity and the characterization of new FTase genes and enzymes are therefore highly desired.

To date, most reports in the literature on the enzymatic synthesis of Suc6A have focused predominantly on lipases, such as Candida rugosa lipase [7], lipozyme TLIM [8], lipase P Amano (Pseudomonas spp.) [28] and lipase TLL (Thermomyces lanuginosus) [29]. Only one fructosyltransferase from Aureobasidium pullulans has been reported to date to catalyze the synthesis of Suc6A from glucose 6-acetate and sucrose [30]. We previously reported the use of Aspergillus oryzae ZZ-01 fructosyltransferase $(A o \mathrm{FT})$ to synthesize Suc6A using glucose 6-acetate (Glu6A) and sucrose as substrates $[9,10]$. However, the industrial application of AoFT from wild-type A. oryzae ZZ-01 has been limited by low yields, and it is therefore necessary to isolate and express the AoFT gene in a bacterial or fungal expression system to improve its productivity. In this study, we describe the molecular cloning and expression of the AoFT gene of A. oryzae ZZ-01 in E. coli, as well as the purification of recombinant $A o \mathrm{FT}(\mathrm{r}-A o \mathrm{FT})$. The enzymatic properties of the $\mathrm{r}-A o \mathrm{FT}$ enzyme were fully characterized, including the structural modeling and experimental analysis of its catalytic triad.

\section{Results and Discussion}

\subsection{Cloning and Sequence Analysis of the aoft Gene}

The aoft fructosyltransferase gene from Aspergillus oryzae ZZ-01 was successfully cloned by RACE and TAIL PCR. The entire aoft gene had an open reading frame of $1578 \mathrm{bp}$ encoding 525 amino acid residues with a putative signal sequence of 19 amino acids. The mature protein was 506 amino acid residues in length and had a calculated molecular mass of $55.4 \mathrm{kDa}$ and a theoretical pI of 4.79. Similar results were observed for the other homologs from A. oryzae N74 and A. oryzae RIB40. Notably, the fructosyltransferase AoFT showed six potential $N$-glycosylation sites (N59, N107, N204, N261, N399 and N437) and six potential O-glycosylation sites (T324, T441, T443, T444, T445 and T516) (Supplementary Figure S1) [1,31]. It was deduced that the amino acid sequence of AoFT showed sequence identities of $98 \%, 96 \%$ and $90 \%$ with the fructosyltransferases from A. oryzae N74 (GU145136), A. oryzae RIB40 (XM_001823193) and A. nomius NRRL 13137 (XM_015553884). The results of our secondary structure prediction suggested that $\mathrm{r}-A o \mathrm{FT}$ consist of a large number of $\beta$-sheets $(48.1 \%$ of the total sequence) and three $\alpha$-helices (2.3\% of the total sequence) (Supplementary Figure S1). Multiple sequence alignment analysis revealed that $\mathrm{r}-A \circ \mathrm{FT}$ contained a typical catalytic triad composed of Asp39-Asp164-Glu216, as well as two conserved motifs (FRDPXVFW and CXXXECPX) containing the active site residue [27,31].

\subsection{Structural Model of $r-A o F T$}

A 3D model structure of $r-A o F T$ was predicted based on the crystal of the fructofuranosidase from Schwanniomyces occidentalis (PDB: 3u75.1A) using the Swiss-Model server. The quality of our predicted $\mathrm{r}-$ AoFT model was assessed using PROCHECK analysis and WHAT IF program. Ramachdarn plot 
indicated (Supplementary Figure S2) that $90.1 \%$ residues in the most favored region, $8.5 \%$ in the additional allowed region and $1.4 \%$ in the disallowed region. The predicted model was subjected to energy minimization using GROMOS96 implemented via Swiss-pdb viewer. The energy of the final model was $-7280.54 \mathrm{KJ} / \mathrm{mol}$, which evaluated the thermodynamic stability of the 3D model. Bond lengths, bond angles and torsion angles of the predicted r-AoFT model were evaluated using the WHAT IF program. The bond lengths (RMS $z$-score of 0.92) and bond angles (RMS $z$-score of 1.15) were found to deviate normally from standard values (a RMS $z$-score for a normally restrained data set is expected to be around 1.0.), respectively. The quality of our predicted r-AoFT model was assessed using the Ramachandran plot and found to be acceptable. The structure of the r-AoFT model consisted of two domains with an $N$-terminal catalytic domain containing a five-fold $\beta$-propeller architecture (residues 11-342) linked to a C-terminal $\beta$-sandwich-like domain (residues 351-511) (Figure 1A). Although we observed considerable differences in the primary structures and properties of $\mathrm{r}-\mathrm{AoFT}$ and its homologs, the 3D structure of $\mathrm{r}-\mathrm{AoFT}$ shared a similar core topology to most of the glycoside hydrolases belonging to glycoside hydrolase families 32 (GH32) 68 (GH68) [32,33]. The active site residue (Asp39) was located in the $N$-terminal fivefold $\beta$-propeller domain, where it could interact with the Gln57, Ser99 and Tyr282 residues located deep inside the central pocket of the $\beta$-propeller domain $[1,31]$. Several hydrogen bonding interactions were observed inside this active-site pocket between Asp39-Gln57, Asp39-Ser99, Ser99-Asp164 and Glu216-Tyr282 (Figure 1B).

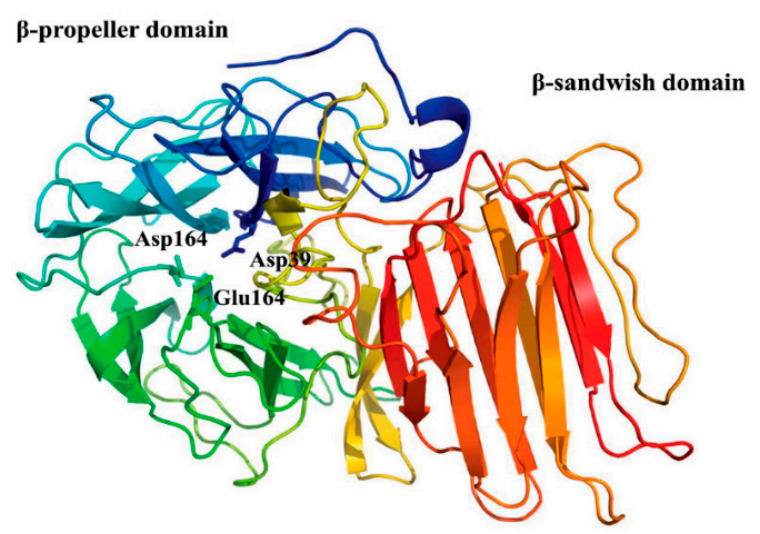

(A)

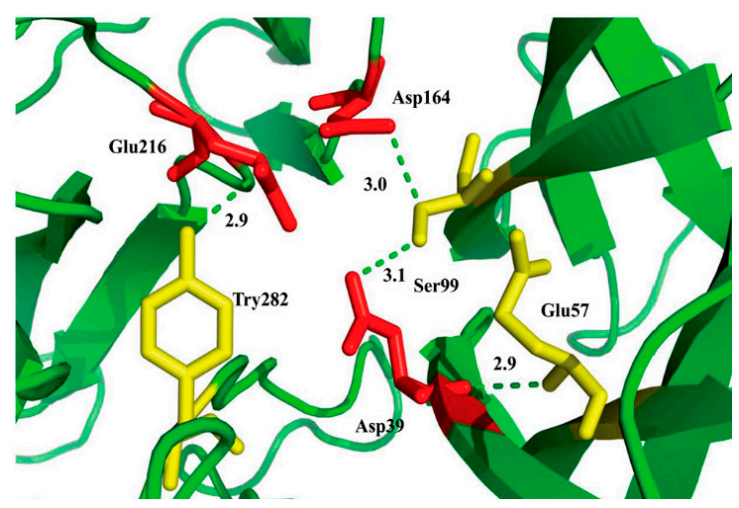

(B)

Figure 1. The predicted 3D structure and active sites of the r-AoFT. (A) The overall structure of $r-A o F T$ consists of a $N$-terminal fivefold $\beta$-propeller domain and a $\beta$-propeller domain. The active sites Asp39, Asp164, and Glu 216 are shown in different colors; (B) The hydrogen bonds with numbering of residues interacting with active sites of $\mathrm{r}-A o \mathrm{FT}$. The corresponding distances are given in $\AA$. The model was generated with the threading program Phyre using the fructofuranosidase from Schwanniomyces occidentalis (PDB: 3u75.1A) as the template.

\subsection{Expression and Purification of $r-A o F T$}

A pET15b-aoft plasmid was constructed for the wild-type enzyme of AoFT to evaluate the biochemical properties of r-AoFT. The r-AoFT enzyme was expressed in E. coli as the His6-r-AoFT fusion protein (calculated to be a $57.4 \mathrm{kDa}$ polypeptide) and purified by Ni-NTA affinity and Superdex-200 gel filtration chromatography. The relative molecular mass of the His6 fusion enzyme $r-A o$ FT was determined to be approximately $60 \mathrm{kDa}$ by SDS-PAGE (Figure 2). The process used for the purification of the $\mathrm{r}-\mathrm{AoFT}$ is summarized in Table 1 . The enzyme was purified 3.5 -fold with a yield of $34.5 \%$ and a specific activity of $38.0 \mathrm{U} / \mathrm{mg}$, which was 38.0 times higher that of the native AoFT enzyme from A. oryzae ZZ-01 [10]. 


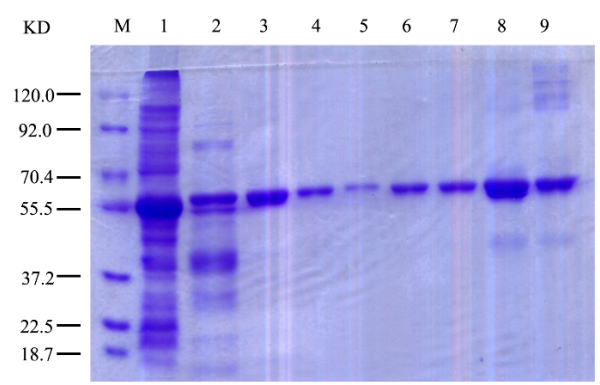

Figure 2. SDS-PAGE of the r-AoFT and the site-directed mutants. Lanes 1, crude cell extract; 2 , the $\mathrm{r}-A o \mathrm{FT}$ after nickel affinity chromatography; 3, the purified $\mathrm{r}-A o \mathrm{FT}$ after Superdex-200 gel filtration chromatography; 4-9, the mutants D39A, D164A, E216A, N38L, S99A and Y282A after gel filtration chromatography.

Table 1. Purification of the r-AoFT from A. oryzae zz-01.

\begin{tabular}{lccccc}
\hline \multicolumn{1}{c}{ Step } & $\begin{array}{c}\text { Total Protein } \\
(\mathbf{m g})\end{array}$ & $\begin{array}{c}\text { Total Activity } \\
\mathbf{( U )}\end{array}$ & $\begin{array}{c}\text { Specific Activity } \\
(\mathbf{U} / \mathbf{m g})\end{array}$ & $\begin{array}{c}\text { Purification } \\
\text { Fold }\end{array}$ & $\begin{array}{c}\text { Yield } \\
(\mathbf{\%})\end{array}$ \\
\hline Crude cell extract & 48.2 & 528.9 & 11.0 & 1 & 100 \\
Heat treatment & 30.1 & 396.7 & 13.2 & 1.2 & 75.0 \\
Ni-NTA affinity & 13.5 & 265.3 & 19.7 & 1.8 & 50.0 \\
Superdex-200 gel filtration & 4.8 & 182.5 & 38.0 & 3.5 & 34.5 \\
\hline
\end{tabular}

\subsection{Effects of Temperature and $\mathrm{pH}$ on Enzyme Activity}

The effects of the temperature and the $\mathrm{pH}$ on the transfructosylation activity were studied at temperature and $\mathrm{pH}$ values in the ranges of $30-80{ }^{\circ} \mathrm{C}$ and 3.5-8.0, respectively, using sucrose and glucose 6-acetate as the substrates (Figure $3 \mathrm{~A}, \mathrm{~B}$ ). The results revealed that the optimum temperature for the activity of $\mathrm{r}-\mathrm{AoFT}$ was $55^{\circ} \mathrm{C}$, which is higher than that of the native $A o \mathrm{FT}$ enzyme from $A$. oryzae ZZ-01 [10], as well as several other recombinant fructosyltransferases $[8,12,13,15,21-23]$. The optimum $\mathrm{pH}$ was for the activity of $\mathrm{r}-A \circ \mathrm{FT}$ was determined to be 5.5 , with the enzyme showing more than half of its maximal activity at $\mathrm{pH}$ values in the range of 4.5-7.0. The thermostability of $\mathrm{r}-\mathrm{AoFT}$ was evaluated at 50,55 and $60^{\circ} \mathrm{C}$ with increasing incubation times of up to $240 \mathrm{~min}$. The activity of the enzyme remained largely unchanged after incubation at $50{ }^{\circ} \mathrm{C}$ for at least $240 \mathrm{~min}$, whereas incubation at $60{ }^{\circ} \mathrm{C}$ for $60 \mathrm{~min}$ led to a reduction in the maximum activity of the enzyme of approximately $35 \%$ (Figure 4). In conclusion, the transfructosylation activity of the r-AoFT enzyme displayed a greater tolerance towards higher temperatures than the wild-type enzyme.

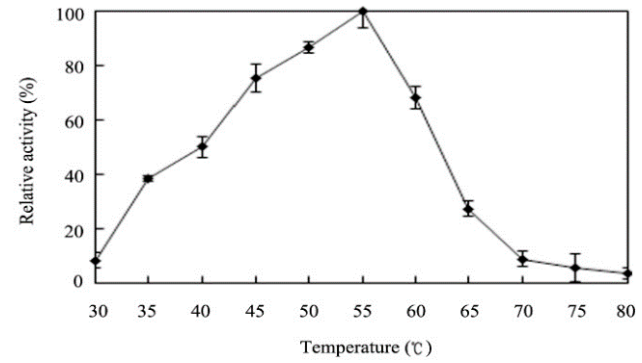

(A)

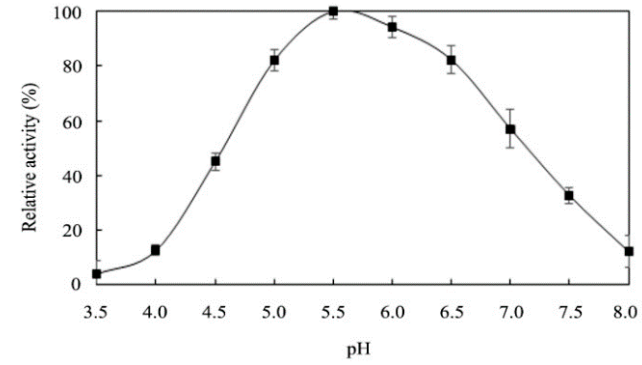

(B)

Figure 3. Temperature optima (A) and $\mathrm{pH}$ optima of the $\mathrm{r}-A o \mathrm{FT}(\mathbf{B})$. (A) Temperature optima of $\mathrm{r}-A o \mathrm{FT}$ was determined with sucrose and glucose 6-acetate as substrates in $50 \mathrm{mM}$ sodium acetate buffer ( $\mathrm{pH}$ 5.5) at temperatures ranging from $30^{\circ} \mathrm{C}$ to $80^{\circ} \mathrm{C} ;(\mathbf{B}) \mathrm{pH}$ optima of the enzyme at pHs ranging from 3.5 to 8.0 was measured for $24 \mathrm{~h}$ at $55^{\circ} \mathrm{C}$. The buffers used were $50 \mathrm{mM}$ of sodium citrate $(\mathrm{pH} 3.5$ to 4.0 ), sodium acetate ( $\mathrm{pH} 4.5$ to 6.0 ), and sodium phosphate ( $\mathrm{pH} 6.5$ to 8.0 ). The values are means of three independent experiments. 


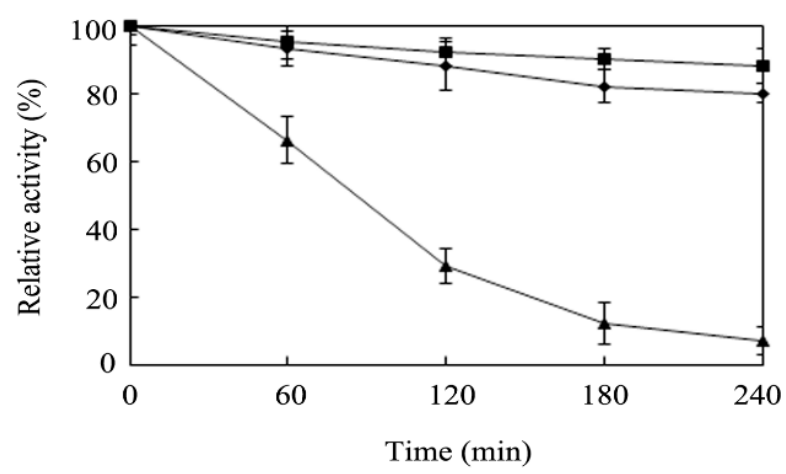

Figure 4. Thermostability of r-AoFT. The residual enzyme activity was measured after incubation of the purified enzyme at $50{ }^{\circ} \mathrm{C}$ (boxes), $55^{\circ} \mathrm{C}$ (diamonds), and $60{ }^{\circ} \mathrm{C}$ (triangles), respectively. The values are means of three independent experiments.

\subsection{Effects of Different Metal Ions, Organic Solvents and Detergents on the Enzymatic Activity of $r$-AoFT}

Some biocatalysts use metal ions, such as $\mathrm{Mg}^{2+}, \mathrm{Zn}^{2+}$ and $\mathrm{Mn}^{2+}$, as co-factors for their enzymatic activities [34]. Metal ions can also induce structural changes that can lead to the denaturation of the enzyme. In this study, we investigated the effects of $5 \mathrm{mM}$ solutions of various metal ions, including $\mathrm{Ca}^{2+}, \mathrm{Mn}^{2+}, \mathrm{Zn}^{2+}, \mathrm{Mg}^{2+}, \mathrm{Cu}^{2+}, \mathrm{Fe}^{2+}, \mathrm{Ni}^{2+}$ and $\mathrm{Co}^{2+}$ ions on the enzymatic activity of the $\mathrm{r}-\mathrm{AoFT}$ enzyme using a standard transfructosylation activity assay. The results revealed that the transfructosylation activity of $\mathrm{r}-\mathrm{AoFT}$ was not significantly affected by the addition of $\mathrm{Ca}^{2+}, \mathrm{Mn}^{2+}, \mathrm{Fe}^{2+}$ or $\mathrm{Co}^{2+}$ ions. The transfructosylation activity was also unaffected by the addition of the chelating reagent EDTA, indicating that this enzyme was not a metalloprotein. The addition of $\mathrm{Mg}^{2+}$ ions led to a $35 \%$ increase in the activity of $\mathrm{r}-\mathrm{AoFT}$, whereas the addition of $\mathrm{Zn}^{2+}, \mathrm{Cu}^{2+}$ or $\mathrm{Ni}^{2+}$ led to a reduction in the activity of the enzyme by $30 \%, 13 \%$ or $8 \%$, respectively (Table 2 ).

Table 2. Effect of various metals and EDTA on the synthesis activity of Suc6A of r-AoFT a .

\begin{tabular}{ccc}
\hline Metals or EDTA & Concentration & Relative Activity (\%) \\
\hline None & - & 100 \\
$\mathrm{Ca}^{2+}$ & $5 \mathrm{mM}$ & $108 \pm 3$ \\
$\mathrm{Mn}^{2+}$ & $5 \mathrm{mM}$ & $103 \pm 1$ \\
$\mathrm{Zn}^{2+}$ & $5 \mathrm{mM}$ & $30 \pm 5$ \\
$\mathrm{Mg}^{2+}$ & $5 \mathrm{mM}$ & $135 \pm 3$ \\
$\mathrm{Cu}^{2+}$ & $5 \mathrm{mM}$ & $13 \pm 2$ \\
$\mathrm{Fe}^{2+}$ & $5 \mathrm{mM}$ & $85 \pm 1$ \\
$\mathrm{Ni}^{2+}$ & $5 \mathrm{mM}$ & $8 \pm 2$ \\
$\mathrm{Co}^{2+}$ & $5 \mathrm{mM}$ & $84 \pm 2$ \\
$\mathrm{EDTA}$ & $5 \mathrm{mM}$ & $92 \pm 1$ \\
\hline
\end{tabular}

a Assay was performed under optimum conditions and the values are means of three independent experiments.

As shown in Table 3, the r-AoFT enzyme retained more than $75 \%$ of its maximum activity following its incubation with methanol, ethanol, acetone, chloroform, toluene, DMF and DMSO at $50 \%(v / v)$. The addition of Tween 20 or Triton-X 100 led to a slight increase in the transfructosylation activity of $\mathrm{r}-\mathrm{AoFT}$, whereas the addition of SDS $(1 \%)$ or urea $(4 \mathrm{M})$ led to a significant reduction in the activity of $\mathrm{r}-A o \mathrm{FT}$ to less than $30 \%$ of its optimal value. The addition of DDT had no discernible impact on the transfructosylation activity of $\mathrm{r}-A o \mathrm{FT}$. Taken together, these results have demonstrated that $\mathrm{r}-A o \mathrm{FT}$ is stable towards various organic solvents, with this material showing similar stability to the native AoFT from A. oryzae ZZ-01[10]. 
Table 3. Effect of organic solvents and detergents on the synthesis activity of Suc6 A of $\mathrm{r}-\mathrm{AoFT}{ }^{\mathrm{a}}$.

\begin{tabular}{ccc}
\hline Organic Solvents or Detergents & Concentration (\%) & Relative Activity (\%) \\
\hline None & - & 100 \\
Methanol & $50(v / v)$ & $92 \pm 5$ \\
Ethanol & $50(v / v)$ & $76 \pm 1$ \\
Acetone & $50(v / v)$ & $83 \pm 2$ \\
Chloroform & $50(v / v)$ & $103 \pm 1$ \\
Toluene & $50(v / v)$ & $112 \pm 3$ \\
DMF & $50(v / v)$ & $89 \pm 2$ \\
DMSO & $50(v / v)$ & $96 \pm 3$ \\
DTT & $5 \mathrm{mM}$ & $94 \pm 2$ \\
Urea & $4 \mathrm{M}$ & $22 \pm 3$ \\
SDS & $1 \%(w / v)$ & $25 \pm 5$ \\
Tween 20 & $1 \%(w / v)$ & $118 \pm 2$ \\
Triton X-100 & $1 \%(w / v)$ & $116 \pm 3$ \\
\hline
\end{tabular}

a Assay was performed under optimum conditions and the values are means of three independent experiments.

\subsection{Identification of Crucial Amino Acid Residue for r-AoFT Activity}

The sequence alignment of the representative $\mathrm{r}-\mathrm{AoFT}$ proteins and their homologs revealed two conserved regions, including FRDPXVFW and CXXXECPX [1,31]. Although it has been predicted that the conserved acidic residues of $\mathrm{r}-A \circ \mathrm{FT}$ could play a significant role in its catalytic activity, there have been no experimental data reported to date to confirm this speculation. To determine the functions of these motifs, we performed several site-directed mutagenesis experiments on $\mathrm{r}-A o \mathrm{FT}$. The vectors required to generate the D39A, D164A, E216A, N38L, S99A and Y282A mutants were constructed using standard techniques, and the resulting mutant proteins were expressed in E. coli. The proteins were then purified using a previously reported procedure for the purification of the wild-type protein [10] to give high quality protein products (Figure 2). The enzymatic properties of the wild-type and mutant enzymes were investigated in detail and the results are summarized in Table 4 . The mutation of several predicted catalytic residues, including Asp39, Asp164 and Glu216 to alanine led to a complete loss of catalytic activity. This result therefore indicated that the Asp39, Asp164 and Glu216 residues in the catalytic site of $\mathrm{r}-\mathrm{AoFT}$ are critical to its transfructosylation activity. Fructosyltransferases operate via a retaining catalytic mechanism, with the Asp39, Asp164 and Glu216 residues acting as a nucleophile, transition-state stabilizer and general acid/base catalyst, respectively. These residues also play a critical role in the binding of the terminal substrate and the catalytic reaction [31,35].

Table 4. Comparison of transfructosylation activity of the wild type r-AoFT and key amino acid mutants.

\begin{tabular}{cccc}
\hline Mutants & $\begin{array}{c}\text { Specific Activities } \\
(\mu \mathbf{m o l} / \mathbf{m i n} / \mathbf{m g})\end{array}$ & $\boldsymbol{K}_{\mathbf{m}}(\boldsymbol{\mu M})$ & $\begin{array}{c}\boldsymbol{V}_{\max } \\
(\mu \mathbf{m o l} / \mathbf{m i n} / \mathbf{m g})\end{array}$ \\
\hline r-AoFT & 38 & 21 & 75 \\
N38L & 42.1 & 24.3 & 89.2 \\
S99A & 40.1 & 22.2 & 81.2 \\
Y282A & 55.2 & 42.1 & 98.2 \\
D39A & 0 & ND & ND \\
D164A & 0 & ND & ND \\
E216A & 0 & ND & ND \\
\hline
\end{tabular}

Compared with the wild type enzyme, the N38L, S99A and Y282A mutant enzymes had lower $K_{\mathrm{m}}$ and higher $V_{\max }$ values, which indicated that they were exhibiting higher binding affinity towards the substrates than the wild type r-AoFT enzyme [36]. Hydrophobic interactions can affect the stability, folding and activity of a protein [37,38]. The results for the N38L, S99A and Y282A mutants revealed that asparagine, serine and tyrosine were acting as hydrophilic residues, whereas alanine and leucine were acting as hydrophobic residues. It was envisaged that the addition of hydrophobic amino acids 
to this enzyme would lead to a decrease in its enzymatic activity. However, the enzymatic activities of the N38V, N38I and Ser99V mutants were very different to those of the N38L and S99A mutants (Supplementary Table S1). Notably, the improved solubility and enzyme activity of these mutants could not be explained in terms of their increased hydrophobic interactions, and were therefore attributed to conformational changes to these mutants. Based on the limitations of the current 3D homology model and modeling methods used in the current study, it was not possible to determine absolutely which of the residues in r-AoFT (beyond the Phe98, Gln214, Pro244 and Trp305 residues) are involved in the recognition and binding of the substrate. Further studies are therefore required, including detailed structural analysis and site directed mutation assays, to develop a complete understanding of the key residues involved in these processes.

\section{Experimental Section}

\subsection{Chemicals, Strains and Plasmids}

The pET15b vector and Escherichia coli strain BL21-CondonPlus (DE3)-RIL were purchased from Stratagene (La Jolla, CA, USA). Pyrobest DNA polymerase, restriction enzymes and DNA ligation kit were bought from Takara (Takara Biotechnology Dalian Co., Ltd., Dalian, China), and used according to the manufacturer's instructions. SMARTer TM RACE cDNA Amplification was purchased from Clontech (Palo Alto, CA, USA). Sucrose and glucose were purchased from Sigma Aldrich (St. Louis, MO, USA). Glucose 6-acetate was supplied by Aoli Co., Ltd. (Zhengzhou, China). Sucrose 6-acetate was purchased from Santa Cruz Biotechnology Co., Ltd. (Shanghai, China). The nickel columns and Superdex 200 gel filtration columns used in the current study were purchased from GE Healthcare (Buckinghamshire, UK). All of the other chemicals were purchased as the highest reagent grade available from Sangon (Shanghai, China).

\subsection{Cloning of the aoft Gene}

A multiple sequence alignment was conducted using three fructosyltransferase sequences from Aspergillus oryzae N74 (GU145136), A. oryzae RIB40 (XM_001823193) and A. oryzae GX0015 (EU181219), and the results revealed two highly conserved peptide fragments (FRDPQVVWH and GDQFECPNL). Based on these conserved sequences, we designed two degenerate primers using the CODEHOP algorithm to amplify a fragment of aoft gene (i.e., upstream, $5^{\prime}$-TTTAGAGAC GGGGNAGTAGTCTGGGAT-3' and downstream, $5^{\prime}$-GGCTACCAATNCGAATGTCCAAATCTC- $3^{\prime}$ ). Genomic DNA from A. oryzae ZZ-1 was used as the template for PCR amplification. The PCR conditions were set as follows: $94{ }^{\circ} \mathrm{C}$ for $1 \mathrm{~min}, 58-62{ }^{\circ} \mathrm{C}$ for $1 \mathrm{~min}, 72{ }^{\circ} \mathrm{C}$ for $2 \mathrm{~min}$ and a final extension at $72{ }^{\circ} \mathrm{C}$ for $10 \mathrm{~min}$. The PCR product was subsequently purified, ligated to a PMD18-T vector and sequenced.

A full-length cDNA fragment of the aoft gene was obtained by $5^{\prime}$ and $3^{\prime}$ RACE using a SMART RACE cDNA Amplification Kit (Clontech, Palo Alto, CA, USA) according to the manufacturer's instructions. The $5^{\prime}$-end of the aoft gene fragment was amplified using an sp1 primer (5'-CCTCGCTGGGGATAAGCCTG-3') with Universal Primer A Mix (UPM) as an adapter primer, followed by a nested PCR using a specific sp2 primer (5'-ACTGGAAACACAGCACATTGC-3') with Nested Universal Primer A (NUP) as an adapter primer. The $3^{\prime}$ RACE process was performed using an sp3 primer (5'-CCGGGCGACCAATTCGAATG-3') with UPM, followed by a nested PCR using a specific sp4 primer (5'-GACTCACAGCCCGTTTGAGGG-3') with NUP. The resulting cDNA sequence of the aoft gene was deposited in the GeneBank database with accession number JN896340. The mature coding sequence of the aoft gene was amplified from the genomic DNA of $A$. oryzae ZZ-1 using the following primers: Forward primer, 5'-GCCCATATGTATATCAAACCATTCATCC-3'; reverse primer, $5^{\prime}$-GATGTCGACCTCGAGTTCTCCAAGGCGCGGAC-3' (the underlined sequences represent the NdeI and SalI sites, respectively). The PCR product was gel-purified and inserted into a pET15b vector, and the resulting plasmid was designated pET15b-aoft. 
Several site-directed mutants, including D39A, D164A, E216A, N38L, S99A and Y282A, were constructed using the overlapping PCR method [39]. The upper fragment was amplified using the forward primer of the wild-type $\mathrm{r}-A o \mathrm{FT}$ and a site-specific downstream primer (Supplementary Table S2), and the lower fragment was amplified using a site-specific upstream primer (Supplementary Table S2) and the reverse primer of the wild-type r-AoFT. After amplification by PCR, the full-length fragment of each mutants was digested with NdeI and SalI and cloned back into pET15b. DNA sequencing was performed to confirm that no unintended mutations had been introduced during the PCR process.

\subsection{Sequence Analysis}

The homologous sequence and conserved domain were identified using the Blastp software provided by the National Center for Biotechnology Information (http://blast.ncbi.nlm.nih. gov/Blast.cgi). Multiple alignment analyses of the deduced amino acid sequences were performed by ClustalW2 (http:/ / www.ebi.ac.uk/Tools/clustalw2/index.html). The three-dimensional structure of $\mathrm{r}-\mathrm{AoFT}$ was generated by homology modelling using the Swiss-Model server (http://swissmodel.expasy.org) using the crystal structure of the Fructofuranosidase from Schwanniomyces occidentalis (PDB: 3u75.1A) as a template. The quality of the resulting 3D model was analyzed by WHAT IF program and PROCHECK analyses, using the Swiss-model workspace. The structure of the 3D model was analyzed and visualized using PyMOL [40]. Signal peptide prediction was carried out using SignalP 3.0 (http://www.cbs.dtu.dk/services/SignalP/). The $\mathrm{N}$ - and O-glycosylation sites were searched using the NetNGlyc 1.0 (http://www.cbs.dtu.dk/services/ NetNGlyc/) and NetOGlyc 3.1 servers (http://www.cbs.dtu.dk/services/NetOGlyc/), respectively.

\subsection{Expression and Purification of Recombinant Fructosyltransferase r-AoFT}

The recombinant plasmid pET15b-aoft was transformed into host E. coli BL21-CodonPlus (DE3)-RIL and the transformed cells were grown in LB medium at $37{ }^{\circ} \mathrm{C}$. When the OD600 value reached 0.5 , gene expression was induced by the addition of $0.5 \mathrm{mM}$ isopropyl- $\beta$-Dthiogalactopyranoside (IPTG). After a further $4 \mathrm{~h}$ of growth at $37^{\circ} \mathrm{C}$, the cells were harvested by centrifugation, resuspended in buffer A ( $50 \mathrm{mM}$ Tris- $\mathrm{HCl}, \mathrm{pH} 8.0,50 \mathrm{mM} \mathrm{NaCl})$ and disrupted by sonication. The soluble fraction was precipitated with ammonium sulfate $(75 \%)$ and the precipitate was suspended in buffer A. The sample was subsequently loaded onto a $\mathrm{Ni}^{2+}$-NTA agarose column (Invitrogen, Carlsbad, CA, USA), which was washed with a buffer containing $20 \mathrm{mM}$ imidazole, before being eluted with elution buffer containing $300 \mathrm{mM}$ imidazole to collect the enzymes. For purification by gel filtration, the samples were dialyzed in buffer A and loaded onto a Superdex 200 gel filtration column (GE Healthcare, Buckinghamshire, UK), which was equilibrated in $50 \mathrm{mM}$ Tris- $\mathrm{HCl}, 100 \mathrm{mM}$ $\mathrm{NaCl}$ buffer (pH 8.0) at $1 \mathrm{~mL} / \mathrm{min}$. The site-directed mutants (D39A, D164A, E216A, N38L, S99A and $\mathrm{Y} 282 \mathrm{~A}$ ) were expressed and purified following the procedure for the wild-type $r-A o F T$ protein. The protein concentration was determined according to the Bradford method.

\subsection{Enzymatic Activity Assay}

The standard reaction mixture $(1 \mathrm{~mL})$ consisting of $0.1 \mathrm{M}$ glucose 6-acetate ( $44 \mathrm{mg}), 0.1 \mathrm{M}$ sucrose (34 mg), $100 \mu \mathrm{L}$ of $50 \mathrm{mM}$ sodium acetate (pH 5.5) and $20 \mu \mathrm{g}$ of purified enzyme. The resulting mixtures were then incubated at $55^{\circ} \mathrm{C}$ for $24 \mathrm{~h}$ with constant shaking at $200 \mathrm{rpm}$. The resulting solutions were analyzed by high-performance liquid chromatography using an Xbridge Amide column $(4.6 \times 250 \mathrm{~mm}$, $3.5 \mu \mathrm{m}$, Waters, USA), as described previously [9,10]. Samples were eluted isocratically with a 3:1 $(v / v)$ mixture of acetonitrile and water at a flow rate of $1 \mathrm{~mL} / \mathrm{min}$. One unit of the transfructosylation activity was defined as the amount of enzyme that catalyzes the conversion of $1 \mu \mathrm{mol}$ glucose 6 -acetate per min. Measurements were corrected for background hydrolysis of the substrate in the absence of the enzyme. 


\subsection{Determination of the Enzymatic Properties of $r$-AoFT}

The optimum temperature of $\mathrm{r}-A o \mathrm{FT}$ was measured in sodium acetate buffer $(\mathrm{pH} 5.5)$ at temperatures in the range of $30-80^{\circ} \mathrm{C}$. The buffer was adjusted to $\mathrm{pH} 5.5$ for each of the assayed temperatures. The effect of $\mathrm{pH}$ on the transfructosylation activity was tested at $55^{\circ} \mathrm{C}$ for $\mathrm{pH}$ values in the range of 3.5-8.0. The following buffers were used in these experiments: sodium citrate $(\mathrm{pH} 3.5$ to 4.0), sodium acetate ( $\mathrm{pH} 4.5-6.0)$, and sodium phosphate ( $\mathrm{pH}$ 6.5-8.0). The thermostability of the purified r-AoFT was examined by incubating the enzyme in $50 \mathrm{mM}$ of sodium acetate buffer ( $\mathrm{pH}$ 5.5) at three different temperatures $\left(50,55\right.$ and $\left.60{ }^{\circ} \mathrm{C}\right)$. Samples $(30 \mu \mathrm{L})$ of the enzyme were collected after incubation periods of $60,120,180$ and $240 \mathrm{~min}$ at the different temperatures and the residual activity of each sample was assayed under the standard conditions. The transfructosylation activity of $\mathrm{r}-\mathrm{AoFT}$ was also measured in the presence of various metal salts $\left(\mathrm{CaCl}_{2}, \mathrm{MnCl}_{2}, \mathrm{ZnCl}_{2}, \mathrm{MgCl}_{2}, \mathrm{CuCl}_{2}\right.$, $\mathrm{FeSO}_{4}, \mathrm{NiSO}_{4}$ and $\mathrm{CoCl}_{2}$ ) and EDTA at $5 \mathrm{mM}$. We also measured the effects of several different organic solvents and detergents on the transfructosylation activity of $\mathrm{r}-\mathrm{AoFT}$ by adding each of the organic solvents $(50 \%, v / v)$ and detergents $(1 \%, v / v)$ to the assay solution. The resulting reaction mixtures were incubated at room temperature for $60 \mathrm{~min}$ and then assayed to determine their transfructosylation activity. The transfructosylation activity of the $\mathrm{r}-\mathrm{AoFT}$ enzyme without an organic solvent or additive was taken as the control and defined as $100 \%$ activity.

\section{Conclusions}

In this study, we have cloned, expressed and characterized a recombinant fructosyltransferase from A. oryzae ZZ-01 (r-AoFT). The transfructosylation activity of r-AoFT was found to be 38.0 times higher that of the wild-type fructosyltransferase from A. oryzae ZZ-01. The optimal temperature and $\mathrm{pH}$ values of the purified enzyme were $55^{\circ} \mathrm{C}$ and 5.5, respectively. Several single-point mutants of this enzyme were prepared, including N38L, S99A and Y282A, which all showed higher transfructosylation activity that the wild-type enzyme. In contrast, the D39A, D164A and E216A mutants exhibited no enzymatic activity. These results therefore demonstrate that $\mathrm{r}-A o \mathrm{FT}$ could be used for the enzymatic synthesis of short-chain sucrose esters of sucrose 6-acetate from sucrose and glucose 6-acetate in biotechnological applications. Furthermore, the elucidation of the 3D structure of r-AoFT is currently underway in our laboratory to determine its catalytic mechanism and substrate recognition properties.

Supplementary Materials: The following are available online at www.mdpi.com/2073-4344/6/5/67/s1. Figure S1: Gene and amino acid sequences of the r-AoFT, Figure S2: Ramacchandran plots of the r-AoFT models by PROCHECK analysis, Table S1: Comparision of transfructosylation activity of the mutants N38L, Ser99A, N38V, N38I and Ser99V, Table S2: Synthetic oligonucleotide primers used for the construction of the site-directed mutants mutants.

Acknowledgments: This work was supported by grants from the National Natural Science Foundation of China (21406210, 21476216 and 21546012); the Innovation Scientists and Technicians Troop Construction Projects of the Henan Province (144200510011); the Henan province foreign cooperation projects (152106000058).

Author Contributions: Tao Wei designed and performed the experiments, analyzed the data and prepared the manuscript. Shen Huang, Jie Zang, and Chunxiao Jia assisted in data analysis. Duobin Mao performed experiments, analyzed the data and assisted in manuscript preparation. All authors read and approved the final manuscript.

Conflicts of Interest: The authors declare no conflict of interest.

\section{References}

1. Alméciga-Díaz, C.J.; Gutierrez, A.M.; Bahamon, I.; Rodríguez, A.; Rodríguez, M.A.; Sánchez, O.F. Computational analysis of the fructosyltransferase enzymes in plants, fungi and bacteria. Gene 2011, 484, 26-34. [CrossRef] [PubMed]

2. Ferrer, M.; Soliveri, J.; Plou, F.J. Synthesis of sugar esters in solvent mixtures by lipase from Thermomyces lanuginosus and Candida Antarctica B, and their antimicrobial properties. Enzym. Microb. Technol. 2005, 36, 391-398. [CrossRef] 
3. Jones, J.D.; Hacking, A.J.; Cheetham, P.S. Biological method for protection of 6-position of sucrose and its use in synthesis of disaccharide high-intensity sweetener. Biotechnol. Bioeng. 1992, 39, 203-210. [CrossRef] [PubMed]

4. Sabeder, S.; Habulin, M.; Knez, Z. Lipase-catalyzed synthesis of fatty acid fructose esters. J. Food. Eng. 2006, 77, 880-886. [CrossRef]

5. Han, Y.W.; Liu, G.M.; Huang, D.Y.; Qiao, B.J.; Chen, L.P.; Guan, L.H.; Mao, D.B. Study on the synthesis of sucrose 6-acetate catalyzed by fructosyltransferase from Aspergillus aryzae. Nat. Biotechnol. 2011, 28, 14-18.

6. Yang, X.; Zheng, P.; Ni, Y.; Sun, Z.H. Highly efficient biosynthesis of sucrose 6-acetate with cross-linked aggregates of Lipozyme TL 100L. J. Biotechnol. 2012, 161, 27-33. [CrossRef] [PubMed]

7. Zhong, X.; Qian, J.Q.; Guo, H.; Hu, Y.Y.; Liu, M. Biosynthesis of sucrose-6-acetate catalyzed by surfactant-coated Candida rugosa lipase immobilized on sol-gel supports. Bioprocess. Biosyst. Eng. 2014, 37, 813-818. [CrossRef] [PubMed]

8. Heyer, A.G.; Wendenburg, R. Gene cloning and functional characterization by heterologous expression of the fructosyltransferase of Aspergillus sydowi IAM 2544. Appl. Environ. Microbiol. 2001, 67, 363-370. [CrossRef] [PubMed]

9. Wei, T.; Yu, X.; Wang, Y.Y.; Zhu, Y.H.; Du, C.C.; Jia, C.X.; Mao, D.B. Purification and evaluation of the enzymatic properties of a novel fructosyltransferase from Aspergillus oryzae: A potential biocatalyst for the synthesis of sucrose 6-acetate. Biotechnol. Lett. 2014, 36, 1015-1020. [CrossRef] [PubMed]

10. Wei, T.; Jia, W.W.; Yu, X.; Mao, D.B. Enhancement of enzymatic synthesis of sucrose 6-acetate with Aspergillus oryzae fructosyltransferase using ionic liquid as a cosolvent. J. Mol. Catal. B Enzym. 2016, 123, 100-106. [CrossRef]

11. Gallagher, J.; Cairns, A.; Pollock, C. Cloning and characterization of a putative fructosyltransferase and two putative invertase genes from the temperate grass Lolium temulentum L. J. Exp. Bot. 2004, 55, 557-569. [CrossRef] [PubMed]

12. Han, Y.W.; Chen, L.P.; Mao, D.B.; Tang, L.J.; Guan, L.H. Expression and activity analysis of sucrose: Sucrose 1-fructosyltransferase from onion. Nat. Biotechnol. 2010, 27, 324-329.

13. Ueno, K.; Onodera, S.; Kawakami, A.; Yoshida, M.; Shiomi, N. Molecular characterization and expression of a cDNA encoding fructan: Fructan 6G-fructosyltransferase from asparagus (Asparagus officinalis). New Phytol. 2005, 165, 813-824. [CrossRef] [PubMed]

14. Arand, M.; Golubev, A.; Neto, J.; Polikarpov, I.; Wattiez, R.; Korneeva, O.; Eneyskaya, E.; Kulminskaya, A.; Shabalin, K.; Shishliannikov, S.; et al. Purification, characterization, gene cloning and preliminary X-ray data of the exo-inulinase from Aspergillus awamori. Biochem. J. 2002, 362, 131-135. [CrossRef] [PubMed]

15. Moriyama, S.; Tanaka, H.; Uwataki, M.; Muguruma, M.; Ohta, K. Molecular cloning and characterization of an exoinulinase gene from Aspergillus niger strain 12 and its expression in Pichia pastoris. J. Biosci. Bioeng. 2003, 96, 324-331. [CrossRef]

16. Isono, N.; Tochihara, T.; Kusnadi, Y.; Win, T.; Watanabe, K.; Obae, K.; Ito, H.; Matsui, H. Cloning and heterologous expression of a $\beta$-fructofuranosidase gene from Arthrobacter globiformis IFO 3062, and site-directed mutagenesis of the essential aspartic acid and glutamic acid of the active site. J. Biosci. Bioeng. 2004, 97, 244-249. [CrossRef]

17. Janer, C.; Rohr, L.; Pelaez, C.; Laloi, M.; Cleusix, V.; Requena, T.; Meile, L. Hydrolysis of oligofructoses by the recombinant $\beta$-fructofuranosidase from Bifidobacterium lactis. Syst. Appl. Microbiol. 2004, 27, $279-285$. [CrossRef] [PubMed]

18. Ryan, S.; Fitzgerald, G.; van Sinderen, D. Transcriptional regulation and characterization of a novel $\beta$-fructofuranosidase-encoding gene from Bifidobacterium breve UCC2003. Appl. Environ. Microbiol. 2005, 71, 3475-3482. [CrossRef] [PubMed]

19. Yuan, X.L.; Goosen, C.; Kools, H.; van der Maarel, M.; van den Hondel, C.; Dijkhuizen, L.; Ram, A.F.J. Database mining and transcriptional analysis of genes encoding inulin-modifying enzymes of Aspergillus niger. Microbiology 2006, 152, 3061-3073. [CrossRef] [PubMed]

20. Goosen, C.; Yuan, X.L.; van Munster, J.; Ram, A.; van der Maarel, M.; Dijkhuizen, L. Molecular and biochemical characterization of a novel intracellular invertase from Aspergillus niger with transfructosylating activity. Eukaryot. Cell 2007, 6, 674-681. [CrossRef] [PubMed] 
21. Yanai, K.; Nakane, A.; Kawate, A.; Hirayama, M. Molecular cloning and characterization of the fructooligosaccharide-producing $\beta$-fructofuranosidase gene from Aspergillus niger ATCC20611. Biosci. Biotechnol. Biochem. 2001, 65, 766-773. [CrossRef] [PubMed]

22. Liebl, W.; Brem, D.; Gotschlich, A. Analysis of the gene for $\beta$-fructosidase (invertase, inulinase) of the hyperthermophilic bacterium Thermotoga maritima, and characterisation of the enzyme expressed in Escherichia coli. Appl. Microbiol. Biotechnol. 1998, 50, 55-64. [CrossRef] [PubMed]

23. Olivares-Illana, V.; Lopez-Munguı, A.; Olvera, C. Molecular characterization of inulosucrase from Leuconostoc citreum: a fructosyltransferase within a glucosyltransferase. J. Bacteriol. 2003, 185, 3606-3612. [CrossRef] [PubMed]

24. Fu, R.; Wang, Y.; Sung, H. Cloning, characterization and functional expression of a new $\beta$-D-fructofuranosidase (Os beta fruct2) cDNA from Oryza sativa. Biotechnol. Lett. 2003, 25, 455-459. [CrossRef] [PubMed]

25. Kawakami, A.; Yoshida, M. Molecular characterization of sucrose: Sucrose 1-fructosyltransferase and sucrose:fructan 6-fructosyltransferase associated with fructan accumulation in winter wheat during cold hardening. Biosci. Biotechnol. Biochem. 2002, 66, 2297-2305. [CrossRef] [PubMed]

26. Lammens, W.; Le Roy, K.; Schroeven, L.; van Laere, A.; Rabijns, A.; van den Ende, W. Structural insights into glycoside hydrolase family 32 and 68 enzymes: functional implications. J. Exp. Bot. 2009, 60, 727-740. [CrossRef] [PubMed]

27. Velazquez-Hernandez, M.L.; Baizabal-Aguirre, V.M.; Bravo-Patino, A.; Cajero-Juarez, M.; Chavez-Moctezuma, M.P.; Valdez-Alarcon, J.J. Microbial fructosyltransferases and the role of fructans. J. Appl. Microbiol. 2009, 106, 1763-1778. [CrossRef] [PubMed]

28. Dordick, J.S.; Hacking, A.J.; Khan, R.A. Selective Acrylation of Sugars. U.S. Patent 5,128,248, 7 July 1992.

29. Fernandez-Lafuente, R. Lipase from Thermomyces lanuginosus: Uses and prospects as an industrial biocatalyst. J. Mol. Catal. B Enzym. 2010, 62, 197-212. [CrossRef]

30. Ratnam, R.; Aurora, S.; Subramaniyam, P. Method of Producing Sucrose-6-Acetate by Whole-Cell Biocatalysis. W.O. Patent 2007/054972 A2, 18 May 2007.

31. Rodriguez, M.A.; Sanchez, O.A.; Almeciga-Diaz, C.J. Gene cloning and enzyme structure modeling of the Aspergillus oryzae N74 fructosyltransferase. Mol. Biol. Rep. 2011, 38, 1151-1161. [CrossRef] [PubMed]

32. Chuankhayan, P.; Hsieh, C.Y.; Huang, Y.C.; Hsieh, Y.Y.; Guan, H.H.; Hsieh, Y.C.; Tien, Y.C.; Chen, C.D.; Chiang, C.M.; Chen, C.J. Crystal structures of Aspergillus japonicas fructosyltransferase complex with donor/acceptor substrates reveal complete subsites in the active site for catalysis. J. Biol. Chem. 2010, 285, 23251-23264. [CrossRef] [PubMed]

33. Bujacz, A.; Jedrzejczak-Krzepkowska, M.; Bielecki, S.; Redzynia, I.; Bujacz, G. Crystal structures of the apo form of $\beta$-fructofuranosidase from Bifidobacterium longum and its complex with fructose. FEBS J. 2011, 278, 1728-1744. [CrossRef] [PubMed]

34. Lombard, V.; Golaconda, R.H.; Drula, E.; Coutinho, P.M.; Henrissat, B. The carbohydrate-active enzymes database (CAZy) in 2013. Nucleic Acids Res. 2014, 42, 490-495. [CrossRef] [PubMed]

35. Van den Ende, W.; Lammens, W.; van Laere, A.; Schroeven, L.; Le Roy, K. Donor and acceptor substrate selectivity among plant glycoside hydrolase family 32 enzymes. FEBS J. 2009, 276, 5788-5798. [CrossRef] [PubMed]

36. Yuan, S.; Le Roy, K.; Venken, T.; Lammens, W.; van den Ende, W.; De Maeyer, M. pKa modulation of the acid/base catalyst within GH32 and GH68: A role insubstrate/inhibitor specificity? PLoS ONE 2012, 7, 1-12. [CrossRef] [PubMed]

37. Aharoni, A.; Gaidukov, L.; Yagur, S.; Toker, L.; Silman, I.; Tawfik, D.S. Directed evolution of mammalian paraoxonases PON1 and PON3 for bacterial expression and catalytic specialization. Proc. Natl. Acad. Sci. USA 2004, 101, 482-487. [CrossRef] [PubMed]

38. Harel, M.; Aharoni, A.; Gaidukov, L.; Brumshtein, B.; Khersonsky, O.; Meged, R.; Dvir, H.; Ravelli, R.B.; McCarthy, A.; Toker, L.; et al. Structure and evolution of the serum paraoxonase family of detoxifying and anti-atherosclerotic enzymes. Nat. Struct. Mol. Biol. 2004, 11, 412-419. [CrossRef] [PubMed] 
39. Kadowaki, H.; Kadowaki, T.; Wondisford, F.E.; Taylor, S.I. Use of polymerase chain reaction catalyzed by Taq DNA polymerase for site-specific mutagenesis. Gene 1989, 76, 161-166. [CrossRef]

40. Kelley, L.; Sternberg, M. Protein structure prediction on the web: A case study using the Phyre server. Nat. Protoc. 2009, 4, 363-371. [CrossRef] [PubMed] 